\title{
EFEKTIFITAS KINERJA DOUBLE SKIN FASADE-GREEN WALL TERHADAP EFISIENSI ENERGI PENDINGINAN BANGUNAN
}

\author{
Cynthia Permata Dewi ${ }^{1}$ dan Anang Bakhtiar ${ }^{2}$ \\ 1,2 Program studi Teknik Sipil, Universitas Islam Malang \\ cwit_gals@yahoo.com
}

\begin{abstract}
ABSTRAK
Strategi pendinginan pasif saat ini cukup banyak diminati dan dipertimbangkan karena efektifitasnya dalam aplikasi di lapangan, salah satunya teknologi double skin façade (DSF) dan green wall. Keduanya memiliki prinsip yang aplikasi dan material yang berbeda namun cukup menarik apabila dikembangkan. Penelitian ini bertujuan untuk melihat efektifitas penggunaan DSF dan DSF-green wall (sebagai pengembangan DSF dan green wall) dalam menurunkan beban energi pendinginan pada bangunan. Studi kasus pada penelitian kali ini dilakukan pada gedung B kampus Unisma, Malang. Simulasi komputer dilakukan dengan menggunakan program designbuilderenergyplus. Aplikasi strategi DSF dan DSF-GW dilakukan pada sisi-sisi terpanjang pada bangunan, yaitu sisi barat dan timur yang menerima panas matahari yang cukup besar. Hasil penelitian menunjukkan bahwa kinerja DSF-green wall cukup efektif menurunkan beban pendinginan bangunan sampai 45\% dibanding DSF konvensional.
\end{abstract}

Kata kunci: Double skin facade, green wall, kinerja, beban pendinginan

\begin{abstract}
Passive cooling strategy has been considered to apply due to its effectiveness. Double skin façade strategy is one of advance building façade technology in passive design. Moreover, Double skin façade-green wall is the development of conventional Double skin façade. The aim of this study is to observe and compare the performance of DSF and DSF-GW in reducing cooling energy. B-block building in Islamic University of Malang has been selected as case study. DesignBuilder-EnergyPlus was used as simulation tool in this study. The strategy of DSF and DSF-GW has been applied in along side of the building. The results show that the DSF-GW resulted best in reducing cooling energy demand up to $45 \%$ compare to conventional DSF.
\end{abstract}

Keywords: Double skin façade, green wall, performance, cooling energy

\section{Pendahuluan}

Pengaruh urban heat island yang salah satunya berdampak pada kenaikan temperature rata-rata kota, salah satunya disebabkan oleh tingkat kepadatan bangunan, dan jenis material penutup tanah yang digunakan, juga berpengaruh terhadap pola hunian di dalam bangunan. Sekitar tahun 1990an, kota Malang merupakan salah satu kota di Indonesia yang memiliki hawa yang cukup sejuk, sehingga pada bangunan dengan fungsi pendidikan yang tidak memerlukan persyaratan khusus misalnya, penghuni dalam bangunan tidak perlu menggunakan bantuan peralatan mekanis untuk mencapai kenyamanan dalam bangunan (thermal comfort). Namun kini, seiring dengan tingkat 
kepadatan bangunan yang cukup tinggi, pola penghuni dalam bangunan ikut berubah. Penggunaan peralatan mekanis menjadi solusi dalam mencapai kenyamanan thermal dalam bangunan. Energi untuk kebutuhan AC pada aktifitas sehari-hari mencapai kisaran 40\%, sedangkan kebutuhan pencahayaan mencapai 35\%.

Berdasarkan penelitian sebelumnya(Dewi, Huang, \& Nugroho, 2013) bahwa untuk mengurangi efek emisi gas rumah kaca, terdapat dua strategi yang bisa digunakan. Pertama, dengan mengurangi suplai energi dan yang kedua melalui pengolahan desain bangunan, sehingga strategi efisiensi dan hemat energi dengan mengurangi kebutuhan konsumsi energi bangunan dapat dicapai.

Fasad bangunan memainkan peranan yang cukup penting terkait dengan kinerja thermal dalam bangunan. Selain itu juga terkait tujuan dari pengolahan fasad bangunan yaitu mengurangi solar gain yang diterima bangunan. Sehingga aplikasi teknologi double skin fasade muncul sebagai salah satu solusi teknis dalam mengurangi penggunaan AC dan mengurangi beban energi pendinginan pada bangunan. Pada penelitian kali ini akan dikembangkan penggunaan tanaman sebagai pengganti kaca yang umumnya digunakan pada DSF konvensional sebagai kulit terluar fasad bangunan. Pengembangan teknologi DSF dengan menggunakan tanaman, belum pernah dilakukan sebelumnya. Sehingga hal ini menjadi menarik untuk diteliti. Penggunaan tanaman yang berbeda akan diaplikasikan secara bersamaan dengan penggunaan jarak air gap yang berbeda pula pada DSF-green wall ini sehingga dapat dilihat pengaruhnya terhadap kinerja penurunan beban energi pendinginan dalam bangunan.

\section{Bahan dan Metode}

\subsection{Double skin fasade}

Definisi DSF (Alessi, 2008) merupakan dinding bangunan tambahan yang pada umumnya transparan dan dipasang di atas dinding eksisting. Ada tiga komponen utama pada strategi DSF ini adalah inner skin (dinding bagian dalam/ dinding eksisting), jarak (cavity/ air gap) dan outer skin (kaca). Kinerja thermal pada strategi yang pada akhirnya berpengaruh terhadap penurunan energi ini merupakan hasil dari perpeaduan performa heat transfer dan thermal buoyancy atau stack effect.

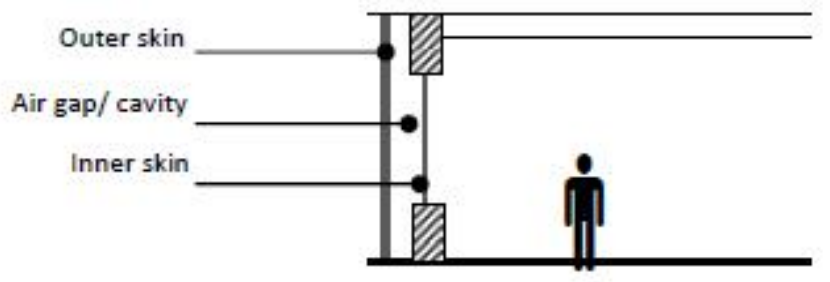

Gambar 1. Komponen DSF

(Sumber: Penulis, 2013)

DSF dibagi menjadi empat tipe, yang pertama adalah box window façade yaitu DSF yang jarak antara dinding luar dan dalam disekat secara vertikal dan horisontal mengikuti bentuk jendela dan berfungsi untuk menghindari transmisi suara dan asap antar ruangan. Tipe yang kedua yaitu shaft box façade yaitu DSF tipe box window yang terhubung dengan saft vertikal yang menerus. Tipe ketiga yaitu corridor façade yaitu DSF yang ruang cavitynya 
disekat secara horisontal sesuai dengan pembagian jumlah lantai bangunan. Tipe yang terakhir yaitu multistory façade yaitu DSF yang ruang antara nya tidak dibagi dan menerus, lubang bukaan untuk ventilasi terdapat di bagian atas dan bawah fasade saja.

\subsection{Double skin fasade - green wall}

DSF-green wall merupakan pengembangan dari strategi konvensional DSF dengan menggunakan tanaman sebagai material outer skin. Ada tiga macam sistem konstruksi untuk strategi ini, yang pertama adalah sistem panel, yang kedua adalah sistem felt dan yang ketiga adalah sistem teralis dan kontainer.
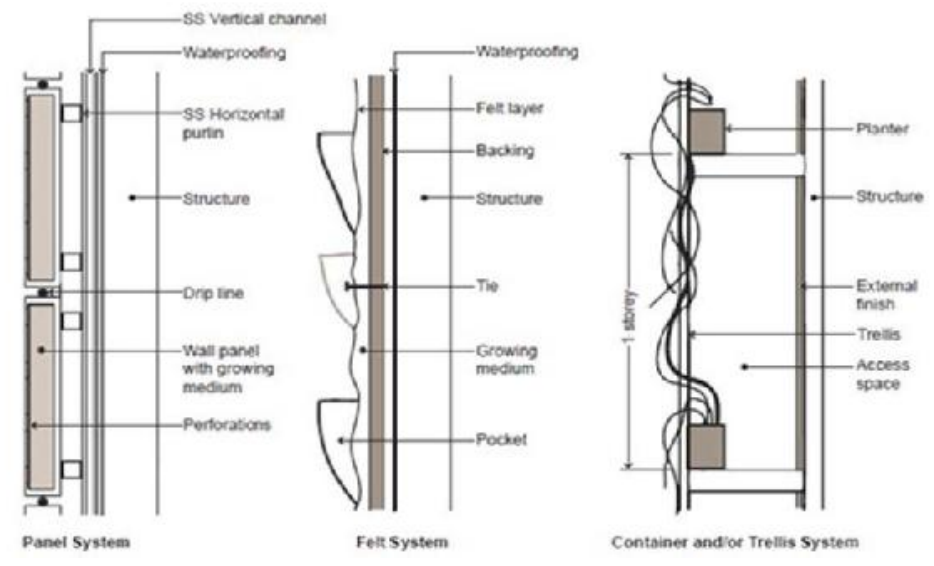

Gambar 2. jenis sistem konstruksi DSF-Green Wall

(Sumber: Loh, 2008)

Ada beberapa prinsip dasar cara kerja DSF-Green wall antara lain: efek pembayangan, pendinginan evaporative, adanya hambatan angin dan adanya perpindahan panas (heat transfer)

\subsection{Metode}

Penelitian ini menggunakan studi kasus sebagai objek dalam meneliti pengaruh penggunaan tanaman sebagai pengganti kaca pada DSF konvensional terhadap penurunan beban energi pendinginan bangunan. Tahapan penelitian dimulai dengan survey literature dan studi ke lapang untuk memperoleh data fisik objek. Gedung kuliah blok B pada kampus Unisma Malang dipiih sebagai objek studi kasus pada penelitian kali ini.

Survey literatur dilakukan untuk memperoleh kebutuhan data untuk variabel elemen tanaman dan air gap yang akan dimodifikasi. Dilakukan seleksi terhadap jenis-jenis tanaman yang biasa digunakan untuk green wall pada iklim kelas $A f$ sesuai peta klasifikasi Köppen (Pérez, Coma, Martorell, \& Cabeza, 2014). Seleksi dilakukan berdasar ketersediaan parameter tanaman yang sesuai dengan input program simulasi. Ada dua jenis tanaman yang sesuai dengan iklim kelas yang terpilih untuk diplikasikan pada penelitian ini, antara lain: Ivy (Hereda helix) dan Tradescantia spathacea.

Variabel lainnya yaitu air gap, juga diperoleh dari studi literatur, berdasarkan jenis air gap yang banyak atau umumnya diaplikasikan pada teknologi DSF (Dewi et al., 2013). Sehingga diperoleh empat jenis air gap, yaitu: $0,3 \mathrm{~m} ; 0,6 \mathrm{~m} ; 0,9 \mathrm{~m}$ dan $1,2 \mathrm{~m}$.

Geometri gedung ini berbentuk persegi panjang dengan ukuran $75 \mathrm{~m}$ x $20 \mathrm{~m}$. gedung ini terdiri dari 7 lantai tipikal. Tinggi antar lantai 3,5m. Sisi terpanjang gedung ini 
merupakan ruang-ruang kelas yang menerima banyak panas matahari pada waktu pagisiang hari. Pada awal gedung ini mulai difungsikan, ruang-ruang kelas tidak dilengkapi dengan pendinginan mekanis. Dan setelah beberapa tahun berfungsi maka karena ketidaknyamanan thermal, maka mulai digunakan bantuan peralatan mekanis untuk membantu kenyamanan penghuni bangunan.
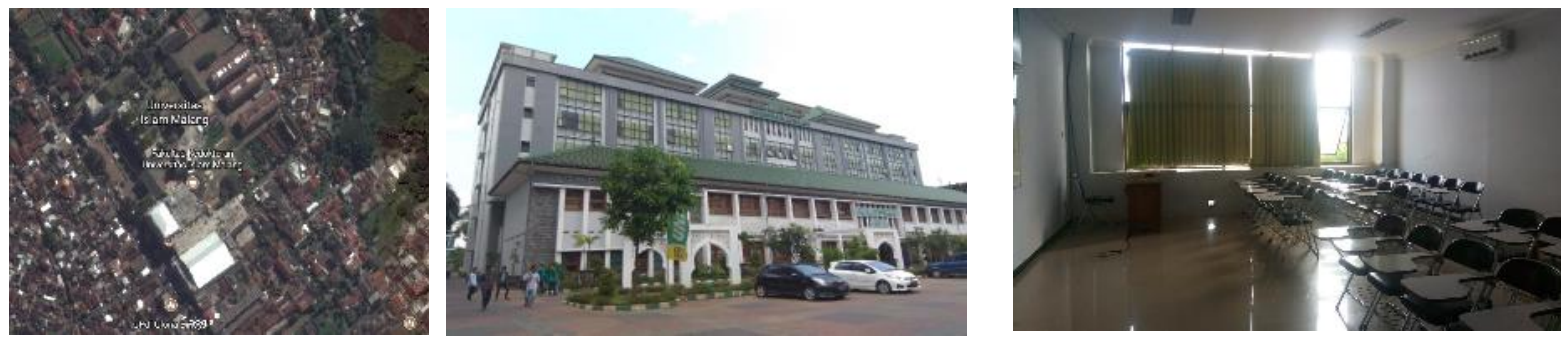

Gambar 3 Foto lokasi, eksterior dan interior objek (Sumber: Penulis, 2017)

Spesifikasi material yang digunakan pada objek dapat dilihat pada Tabel 1:

Tabel 1. Material properties gedung blok B Unisma

\begin{tabular}{|c|c|c|}
\hline Element & U-Value $\left(\mathrm{W} / \mathrm{m}^{2} \mathrm{~K}\right)$ & Image \\
\hline External wall & 2,368 & 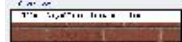 \\
\hline Partition & 1,639 & \\
\hline & & $\cdots$ \\
\hline Internal floor & 2,756 & \\
\hline
\end{tabular}

Model DSF-green wall merupakan pengembangan dari model DSF konvensional. Berdasarkan penelitian sebelumnya model DSF konvensional yang memiliki kinerja terbaik merupakan DSF dengan lebar air gap 1,2m dan outer skin material double glazed Low-E. sehingga parameter tersebut akan diaplikasikan pada simplifikasi aktual model. Hasil simulasi DSF-green wall yang menghasilkan kinerja efisiensi energi terbaik akan dibandingkan dengan model DSF konvensional. Parameter modifikasi DSF dan DSF-green wall dapat dilihat pada Tabel 2 .

Tabel 2. Parameter DSF

\begin{tabular}{|c|c|c|c|}
\hline \multicolumn{2}{|c|}{ DSF-GREEN WALL } & \multicolumn{2}{|c|}{ DSF KONVENSIONAL } \\
\hline $0,3 \mathrm{~m}$ & - Ivy (Hereda helix) & $0,3 \mathrm{~m}$ & double glazed Low-E \\
\hline $0,6 \mathrm{~m}$ & Tradescantia spathacea & $0,6 \mathrm{~m}$ & \\
\hline $0,9 \mathrm{~m}$ & & $0,9 \mathrm{~m}$ & \\
\hline $1,2 \mathrm{~m}$ & & $1,2 \mathrm{~m}$ & \\
\hline
\end{tabular}


Simulasi dijalankan menggunakan data iklim perjam kota Malang yang diperoleh dari stasiun BMKG kota Malang yang terbaru yaitu data tahun 2016. Data diolah melalui program epw creator supaya dapat diinput pada program simulasi designbuilder-energyplus.

\section{Hasil dan Pembahasan}

Tahapan pertama adalah melakukan simulasi pada model dasar atau eksisting model. Sebelum dilakukan running simulasi maka dilakukan penyederhanaan pada simulasi ini selain karena keterbatasan program (versi trial terbatas 50 zona thermal) juga untuk mempersingkat waktu simulasi. Model dasar merupakan model actual yang disederhanakan dan tanpa modifikasi elemen fasad apapun yang kemudian disimulasi dan hasilnya akan menjadi acuan perbandingan kinerja aplikasi DSF-green wall.

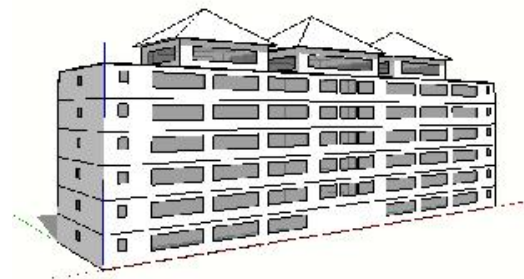

Model aktual

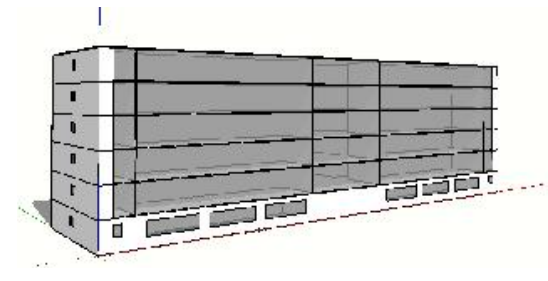

Simplifikasi

Gambar 4. Simplifikasi model

(Sumber: Penulis, 2017)

Hasil simulasi model dasar menunjukkan bahwa total konsumsi energi bangunan untuk pendinginan dalam kurun waktu satu tahun adalah 4.219 MWh. Setelah simulasi model dasar dilakukan, kemudian dilakukan simulasi pada kedelapan model alternatif DSFgreen wall dan DSF konvensional menggunakan double glazed low-E. Hasil simulasi alternatif model DSF-green wall dan DSF konvensional ditampilkan pada Tabel 3.

Tabel 3. Hasil simulasi DSF-green wall dan DSF konvensional

\begin{tabular}{|l|l|l|l|l|}
\hline \multicolumn{5}{|c|}{ DSF-green wall } \\
\hline & $0,3 \mathrm{~m}$ & $0,6 \mathrm{~m}$ & $0,9 \mathrm{~m}$ & $1,2 \mathrm{~m}$ \\
\hline Ivy (Hereda helix) & 3.400 & 3.419 & 3.440 & 3.461 \\
\hline$\%$ penurunan energi pendinginan & $19 \%$ & $19 \%$ & $18 \%$ & $17 \%$ \\
\hline Tradescantia spathacea & 2.316 & 2.331 & 2.346 & 2.361 \\
\hline \% penurunan energi pendinginan & $45 \%$ & $45 \%$ & $45 \%$ & $44 \%$ \\
\hline \multicolumn{5}{|c|}{ DSF konvensional } \\
\hline Double glazed low-E & 3.887 & 3.875 & 3.813 & 3.827 \\
\hline$\%$ penurunan energi pendinginan & $7 \%$ & $8 \%$ & $9 \%$ & $9 \%$ \\
\hline
\end{tabular}

Hasil simulasi menunjukkan bahwa pada penggunaan DSF-green wall, penurunan energi terbesar dicapai pada saat penggunaan material tanaman Tradescantia spathacea sebagai material kulit terluar dan jarak air gap 0,3m. Penurunan energi pendinginan yang terjadi pada alternatif tersebut sebesar $45 \%$ (2.316MWh). Sedangkan penurunan energi terkecil diperoleh pada penggunaan Ivy (Hereda helix) dengan penurunan energi sebesar $17 \%$ (3.461 MWh).

Dari hasil simulasi dapat dilihat bahwa pada penggunaan jarak air gap yang kecil, penurunan energi pendinginan yang terjadi justru semakin besar. Hal ini dapat dijelaskan oleh salah satu mekanisme thermal strategi green wall yaitu adanya pendinginan 
evaporative. Pada prinsipinya pendinginan evaporative ini dapat berfungsi untuk menurunkan suhu dan menaikkan tingkat kelembaban di sekitar bangunan, sehingga semakin dekat jarak antara tanaman dengan dinding maka semakin dingin pula ruangan di sekitarnya (suhu ruangan menjadi turun), sebaliknya pada penggunaan jarak yang terlalu lebar mekanisme pendinginan evaporative tidak dapat bekerja secara maksimal. Akibatnya pada penggunaan jarak air gap yang besar maka penurunan suhu yang terjadi pada ruangan di sekitarnya menjadi kecil.

Berbeda pada penggunaan strategi DSF konvensional, pada aplikasi DSF dengan double glazed low-E sebagai outer skin, penurunan energi terbesar terjadi seiring dengan semakin besarnya jarak air gap antara outer skin (double glazed low-E) dengan dinding eksisting. Konsep transfer panas pada strategi DSF konvensional adalah adanya pemanfaatan air gap sebagai layer tambahan yang berfungsi mengurangi radiasi sinar $U V$ yang masuk ke dalam bangunan. Penurunan energi terbesar diperoleh pada penggunaan air gap $1,2 \mathrm{~m}$ yaitu sebesar $9 \%$.

\section{Simpulan}

Dari penelitian yang telah dilakukan dapat disimpulkan bahwa strategi DSF memiliki potensi untuk diaplikasikan pada wilayah iklim tropis lembab seperti di Indonesia karena secara umum dapat menurunkan energi pendinginan pada bangunan.

Pada aplikasi DSF-green wall, besarnya penurunan energi berbanding terbalik dengan besarnya jarak air gap pada bangunan. Hal ini terkait dengan mekanisme dan prinsip pendinginan evaporative yang terjadi akibat penggunaan tanaman. Penurunan energi terbesar yaitu sebesar $45 \%$ pada strategi ini terjadi pada penggunaan material Tradescantia spathacea dengan jarak air gap $0,3 \mathrm{~m}$.

Berbeda dengan DSF-green wall, pada penggunaan DSF konvensional, penurunan energi yang terbesar justru terjadi sebanding dengan semakin besarnya jarak air gap antara kulit terluar (double glazed low-E) dengan dinding eksisting (Dewi et al., 2013). Penurunan energi yang terbesar adalah 9\% yang diperoleh dari penggunaan jarak air gap 1,2m.

Dari aplikasi kedua strategi yang telah diteliti, dapat dilihat bahwa penggunaan DSFgreen wall memiliki kinerja yang lebih baik dibanding DSF konvensional dalam menurunkan energi pendinginan pada bangunan.

\section{Ucapan Terima Kasih}

Ucapan terima kasih kami sampaikan kepada: Direktorat Penelitian dan Pengabdian Kepada Masyarakat Direktorat Jenderal Pendidikan Tinggi Kementerian Pendidikan dan Kebudayaan; dan BMKG Karangploso, Malang

\section{Daftar Pustaka}

Alessi, B. (2008). Double Skin façade and its benefits. Copenhagen: Copenhagen Technical Academy.

Dewi, C. P., Huang, R.-Y., \& Nugroho, A. M. (2013). Strategi Double Skin Fasade pada Bangunan Kampus National Central University dalam Menurunkan Kebutuhan Energi Pendinginan. Jurnal RUAS. 
Pérez, G., Coma, J., Martorell, I., \& Cabeza, L. (2014). Vertical Greenery Systems (VGS) for energy saving in buildings:A review. RenewableandSustainableEnergyReviews, 39, $139-165$.

Loh, Susan. (2008). Living Walls- A way to Green the Built Environment. Design Guide.

G. Pérez, J. Coma, I. Martorell, and L. Cabeza. (2014). Vertical Greenery Systems (VGS) for energy saving in buildings:A review. RenewableandSustainableEnergyReviews, vol. 39, pp. 139-165

P. Passerini M., P. Brebbia G., and Latini. (2012). Vertical vegetation design decisions and their impact on energy consumption in subtropical cities. Presented in The Sustainable City VII : Urban Regeneration and Sustainability, WIT Press pp. 489-500.

S. F. Larsen, C. Filippín, and G. Lesino. (2014). Thermal simulation of a double skin façade with plants. Energy Procedia, vol. 57, pp. 1763 - 1772

Tsay,Y.S., Lin, J., Y., and Lin, C.H. (2016). The influence of vertical greenery on mansion balcony to indoor thermal environment in sub-tropical climate areas. Part 2: simulation of the reduction of annual heat load by vertical greenery. 